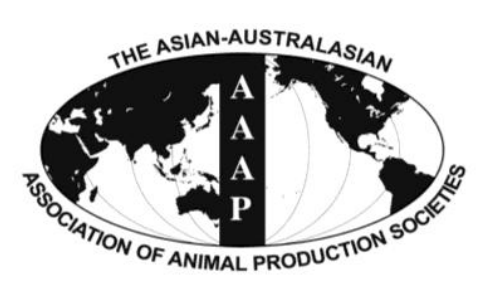

Open Access

Asian Australas. J. Anim. Sci.

Vol. 28, No. 3 : 334-342 March 2015

http://dx.doi.org/10.5713/ajas.14.0480

pISSN 1011-2367 elSSN 1976-5517

\title{
Reproductive Performance of Holstein Dairy Cows Grazing in Dry-summer Subtropical Climatic Conditions: Effect of Heat Stress and Heat Shock on Meiotic Competence and In vitro Fertilization
}

\author{
Krishna Pavani, Isabel Carvalhais, Marwa Faheem ${ }^{1}$, Antonio Chaveiro, \\ Francisco Vieira Reis ${ }^{2}$, and Fernando Moreira da Silva* \\ Department of Agrarian Sciences, \\ CITA-A (Research Centre for Agricultural and Environmental Sciences and Technology of the Azores), \\ Animal Reproduction, University of the Azores, Angra do Heroísmo 9700-042, Portugal
}

\begin{abstract}
The present study was designed to evaluate how environmental factors in a dry-summer subtropical climate in TerceiraAzores (situated in the North Atlantic Ocean: $38^{\circ} 43^{\prime} \mathrm{N} 27^{\circ} 12^{\prime} \mathrm{W}$ ) can affect dairy cow (Holstein) fertility, as well as seasonal influence on in vitro oocytes maturation and embryos development. Impact of heat shock (HS) effects on in vitro oocyte's maturation and further embryo development after in vitro fertilization (IVF) was also evaluated. For such purpose the result of the first artificial insemination (AI) performed 60 to 90 days after calving of 6,300 cows were recorded for one year. In parallel, climatic data was obtained at different elevation points $(\mathrm{n}=5)$ from 0 to $1,000 \mathrm{~m}$ and grazing points from 0 to $500 \mathrm{~m}$, in Terceira island, and the temperature humidity index (THI) was calculated. For in vitro experiments, oocytes $(n=706)$ were collected weekly during all year, for meiotic maturation and IVF. Further, to evaluate HS effect, 891 oocytes were collected in the cold moths (December, January, February and March) and divided in three groups treated to HS for $24 \mathrm{~h}$ during in vitro maturation at: $\mathrm{C}\left(\mathrm{Control}=38.5^{\circ} \mathrm{C}\right)$, $\mathrm{HS} 1\left(39.5^{\circ} \mathrm{C}\right)$ and $\mathrm{HS} 2\left(40.5^{\circ} \mathrm{C}\right)$. Oocytes from each group were used for meiotic assessment and IVF. Cleavage, morula and blastocyst development were evaluated respectively on day 2, 6, and 9 after IVF. A negative correlation between cow's conception rate (CR) and THI in grazing points $(-91.3 \%$; p<0.001) was observed. Mean THI in warmer months (June, July, August and September) was $71.7 \pm 0.7$ and the CR $(40.2 \pm 1.5 \%)$ while in cold months THI was $62.8 \pm 0.2$ and CR was $63.8 \pm 0.4 \%$. A similar impact was obtained with in vitro results in which nuclear maturation rate (NMR) ranged from $78.4 \%( \pm 8.0)$ to $44.3 \%( \pm 8.1)$, while embryos development ranged from $53.8 \%( \pm 5.8)$ to $36.3 \%( \pm 3.3)$ in cold and warmer months respectively. In vitro HS results showed a significant decline $(\mathrm{p}<0.05)$ on NMR of oocytes for every $1{ }^{\circ} \mathrm{C}$ rising temperature (78.4 $\pm 8.0,21.7 \pm 3.1$ and $8.9 \pm 2.2$, respectively for C, HS1, and HS2). Similar results were observed in cleavage rate and embryo development, showing a clear correlation $(96.9 \mathrm{p}<0.05)$ between NMR and embryo development with respect to temperatures. Results clearly demonstrated that, up to a THI of 70.6, a decrease in the CR occurs in first AI after calving; this impairment was confirmed with in vitro results. (Key Words: Environmental Stress, Artificial Insemination, Heat Shock, Oocyte Meiotic Maturation, Maternal Heat Stress)
\end{abstract}

\section{INTRODUCTION}

The sum of external forces acting on homeothermic

\footnotetext{
* Corresponding Author: Fernando Moreira da Silva. Tel: $+351-$ 295-402200, Fax: +351-295-402209, E-mail: jsilva@uac.pt

Department of Animal Production Science, Faculty of Agriculture, Cairo University, 12613 Giza, Egypt.

2 Centre of Climate, Meteorology and Global Change of the University of the Azores, Angra do Heroísmo 9700-042, Portugal. Submitted Jul. 2, 2014; Revised Oct. 14, 2014; Accepted Nov. 2, 2014
}

animal to alter body temperature from the ideal temperature is termed as heat stress (Yousef, 1985). The negative effect of high ambient temperatures on reproductive processes has been documented (e.g. Putney et al., 1989; Edwards and Hansen, 1997; Lawrence et al., 2004) in various domestic species. In a review paper, Alexander (2010) described that hot environments increase blood, rectal and uterine temperatures and also suppress fertility, puberty, spermatogenesis, ovarian cyclicity, ovulation, oogenesis and embryogenesis. According to research conducted by

Copyright $@ 2015$ by Asian-Australasian Journal of Animal Sciences This is an open-access article distributed under the terms of the Creative Commons Attribution Non-Commercial License (http://creativecommons.org/licenses/by-nc/3.0/) which permits unrestricted non-commercial use, distribution, and reproduction in any medium, provided the original work is properly cited. 
Badinga et al. (1993) in Florida, United States (US) conception rates of lactating Brown Swiss, Jersey and Holstein cows decreased from $52 \%$ to $32 \%$ as maximum air temperature increased from $23.9^{\circ} \mathrm{C}$ to $32.2^{\circ} \mathrm{C}$ during summer. Moreover in Brazil the pregnancy rates of Holstein cows in free stall were reduced from $71.2 \%$ in winter to $45.7 \%$ in the summer (Pires et al., 2002). Research developed by Torres-Junior et al. (2008) reported, that Bos indicus species (zebu) have greater thermoregulatory efficiency than Bos taurus (European) because of lower internal heat production and heat dissipation to the environment, leading Bos indicus breeds to be more resistant to hyperthermia. Bos taurus lactating cows are more susceptible to heat stress since high metabolic heat production associated with lactation predisposes them to hyperthermia (Yaser et al., 1999) and for this reason, fertility of heifers is less affected by heat stress (Badinga et al., 1985). Heat stress leads to the decrease in fertility and also affects physiological, cellular functions in several tissues, the leading outcome of which is damage to antral follicles. Therefore, three to four estrous cycles are needed to recover fertility (Roth et al., 2001). Heat stress is particularly harmful for the oocytes as they are exposed to heat stress 3 days before and 1 day after insemination, which mainly affects follicle development and oocytes competence during maturation (Hansen et al., 2001). Maturation of oocytes is usually associated with nuclear and cytoplasmic events. Cytoplasmic maturation manifests as changes in protein contents as well as in the redistribution of organelles such as cortical granules playing a crucial role in nuclear maturation (Ducibella and Buetow, 1994). A cortical granule migrates from Golgic apparatus to the vitelline surface, assuming a position 0.4 to $0.6 \mu \mathrm{m}$ below the plasma membrane (Hosoe and Shioya, 1997) which undergoes exocytosis by fusing with the egg membrane, releasing cortical granules contents in to perivitelline space. This is an important step in membrane maturation and blockage of polyspermy (Wang et al., 1997).

As most research on heat shock in bovine is conducted by exposing females to different heat shock situations, the present study was designed to not only evaluate reproductive performances of all day grazing Holstein cows in a warm temperature region of Azores, in relation to environmental stress, but also to determine the in vitro development of oocytes and embryos during cold and warmer months. The effect of heat shock under different temperatures during in vitro maturation (IVM) of bovine oocytes and further embryonic development after in vitro fertilization (IVF) was also evaluated.

\section{MATERIAL AND METHODS}

\section{Experimental design}

The present study is a two part experiment involving studies of heat stress and heat shock (HS). In the first part of the experiment, breeding records of artificial insemination (AI) in dairy Holstein-Friesian cows $(\mathrm{n}=$ 6,300) located in Terceira-Azores (situated in the North Atlantic Ocean: $38^{\circ} 43^{\prime} \mathrm{N} 27^{\circ} 12^{\prime} \mathrm{W}$ ), were taken from January to December 2012. In parallel, climatic data was also recorded.

As second part of the experiment, oocytes $(n=706)$ were aspirated based on the cold and warmer months and divided in to two groups: one for meiotic maturation $(\mathrm{n}=$ $249)$ and other for IVF $(n=457)$. Apart from this, in the cold season, oocytes $(n=891)$ were aspirated and maturated for $24 \mathrm{~h}$ at three different temperatures: group 1 as control $\left(38.5^{\circ} \mathrm{C}\right)(\mathrm{n}=285)$, group 2 as $\operatorname{HS} 1\left(39.5^{\circ} \mathrm{C}\right)(\mathrm{n}=$ $324)$ and group $3 \mathrm{HS} 2\left(40.5^{\circ} \mathrm{C}\right)(\mathrm{n}=282)$ mimicking cows rectal temperatures during hot seasons, as they vary from $39.1^{\circ} \mathrm{C}$ to $42^{\circ} \mathrm{C}$ (Ealy et al., 1993). After maturation all oocytes were considered for cumulus expansion. Then, from the 285 oocytes of control group, 125 were fixated and dyed for nuclear maturation and the other 160 oocytes were fertilized in vitro as previously described by Faheem et al. (2011), with results evaluated to 9 days after fertilization. This procedure was repeated for group 2 (157 vs 167) and for group 3 (122 vs 160). In experiment 2 each test was repeated five times and data from each experiment were pooled.

\section{Artificial insemination data, conception rate and climatic data}

Only the result of the first insemination of lactating cows performed 60 to 90 days after calving by a local AI agency (UNICOL) were taken. Animals were considered pregnant if they did not exhibit oestrus 90 days after AI. Climatic data was obtained from the CLIMAAT (Centre of Climate, Meteorology and Global Change) project as previously described by Azevedo (1996), at five different elevation points ( 0 to $1,000 \mathrm{~m}$ altitude) placed randomly around the island. Additionally climatic data was also recorded in grazing areas where dairy farms were located. Data of all points were recorded considering maximum and minimum temperature (Tmax, $\operatorname{Tmin}{ }^{\circ} \mathrm{C}$ ) and maximum and minimum relative humidity (RHmax, RHmin), as well as rain fall $(\mathrm{mm})$. Temperature humidity index (THI) was calculated using the formula purposed by Garcia-Ispierto et al. (2007):

$$
\mathrm{THI}=[0.8 \times \mathrm{Tmax}+(\mathrm{RHmin}(\%) / 100) \times(\mathrm{Tmax}-14.4)+46.4]
$$

\section{Collection of oocytes}

The chemicals and reagents used in the experiment were obtained from Sigma-Aldrich (St. Louis, MO, USA). Ovaries were harvested once a week for one year from Holstein cows from a local abattoir, trimmed of adhering 
tissue and transported to the laboratory in Dulbecco's phosphate buffered saline (DPBS) at a temperature ranging from $34^{\circ} \mathrm{C}$ to $37^{\circ} \mathrm{C}$ within $2 \mathrm{~h}$ post slaughtering. All ovaries were rinsed once with $70 \%$ alcohol and followed by a wash with fresh DPBS upon arrival at laboratory.

\section{In vitro maturation, nuclear staining and in vitro fertilization}

Cumulus oocytes complexes (COCs) were collected by aspiration from antral follicles (2 to $8 \mathrm{~mm}$ diameter) with 18 gauge needle. Good quality COCs based on their morphological appearance (covered by at least four layers of compacted cumulus cells and evenly granulated ooplasm), were washed twice in Tissue Culture Medium 199 (TCM-199) supplemented with $2 \%$ foetal bovine serum (FBS), $0.3 \mathrm{mg} / \mathrm{mL}$ glutamine and $50 \mu \mathrm{g} / \mathrm{mL}$ gentamycin and. Oocytes collected in cold and warm seasons were cultured for $24 \mathrm{~h}$ and based on cumulus expansion they were divided into two groups. One group were subjected to IVF (Faheem et al., 2011) and in the other group, oocytes were denuded by vortexing and fixated in 3:1 (Methonal:glacial acetic acid) solution for $24 \mathrm{~h}$ at room temperature by air tighten up the petri dish with parafilm. After fixation each denuded oocytes were dyed with $1 \%$ Orcein and their meiosis stages were recorded. Apart from this, oocytes collected in cold seasons were also submitted to heat stress, being maturated at $39.5^{\circ} \mathrm{C}$ (HS1) and $40.5^{\circ} \mathrm{C}$ (HS2) for $24 \mathrm{~h}$. Oocytes maturated in heat stress were subjected to dying and IVF as mentioned above.

\section{Statistical analysis}

All the climatic, conception rate (CR) data's liner and logistic regression analyses were performed by SPSS package, version 17.0 (SPSS INC., Chicago, IL, USA) using monthly THI, Tmax, Rhmin as independent variables and $\mathrm{CR}$ as dependent variable. The effects of the independent variables were tested in lactating cows group to evaluate the statistical significance $(\mathrm{p}<0.05)$. In experiment 2 , to determine the effect of heat shock and environmental stress in each experiment, data were analysed by using the $\mathrm{t}$-test to assess whether the means were statistically different from each other. Standard deviation and standard error of the mean of each mean was also calculated.

\section{RESULTS}

\section{In vivo effects of environmental stress on conception rate}

On average of all the points, maximum temperatures were recorded in the months of June, July, August and September and the lowest in December, January, February, and March (Table 1). No substantial changes were identified in relative humidity levels of both maximum and minimum in the entire island throughout all the months. Highest rain fall was registered in December, January, February and lowest was in June, July and August. By comparing THI of elevation and grazing points, no considerable changes were observed. Monthly THI levels of all elevation and grazing are plotted in Figure 1.

The number of cows inseminated per month was about the same among all year. Out of the total of 6,300 artificially inseminated Holstein cows, 3,300 (55.0\%) became pregnant on the first insemination after calving. These results were maximum in winter/spring $(63.8 \% \pm 0.4)$ and minimum in summer/autumn $(40.2 \% \pm 1.5)$. A negative correlation $(-91.3 \%, \mathrm{p}<0.001)$ was observed between THI of grazing points and CR. During February and March when THI was lowest $(56.6 \pm 1.9$ and $57.5 \pm 1.9$, respectively) the CR was highest $(64.2 \%$ and $64.9 \%$, respectively). The opposite was observed in July and August when THI was highest $(71.1 \pm 2.9$ and $73.8 \pm 2.2)$ and CR was lowest $(36.8 \%$ and $37.5 \%$ ) (Figure 2).

\section{In vitro effect of colder and warmer months}

A pronounced effect of warmer vs colder months was

Table 1. Mean monthly temperatures, humidity, and rainfall conditions in, Terceira island, for the study period (year of 2012)

\begin{tabular}{lcccccc}
\hline Months & Tmax $\left({ }^{\circ} \mathrm{C}\right)$ & $\mathrm{T} \min \left({ }^{\circ} \mathrm{C}\right)$ & RHmin $(\%)$ & RHmax $(\%)$ & THI & Rain fall $(\mathrm{mm})$ \\
\hline January & $17.3 \pm 1.1$ & $6.0 \pm 1.2$ & $84.2 \pm 3.6$ & $85.3 \pm 2.0$ & $62.6 \pm 1.9$ & $282.9 \pm 62.4$ \\
February & $17.0 \pm 1.1$ & $10.5 \pm 1.2$ & $83.6 \pm 3.5$ & $84.3 \pm 2.0$ & $62.1 \pm 1.9$ & $250.7 \pm 53.8$ \\
March & $17.8 \pm 1.1$ & $11.3 \pm 1.2$ & $76.4 \pm 3.5$ & $85.5 \pm 1.8$ & $63.2 \pm 1.9$ & $220.9 \pm 43.1$ \\
April & $18.8 \pm 1.1$ & $11.0 \pm 1.2$ & $75.7 \pm 3.4$ & $85.4 \pm 1.8$ & $64.7 \pm 1.8$ & $203.8 \pm 37.9$ \\
May & $20.0 \pm 1.1$ & $12.8 \pm 1.3$ & $75.6 \pm 3.3$ & $89.2 \pm 1.7$ & $66.6 \pm 1.7$ & $130.6 \pm 19.1$ \\
June & $23.0 \pm 1.0$ & $12.5 \pm 1.1$ & $80.7 \pm 3.0$ & $87.4 \pm 1.6$ & $71.6 \pm 1.6$ & $112.3 \pm 15.8$ \\
July & $23.8 \pm 1.1$ & $13.8 \pm 1.1$ & $80.4 \pm 3.1$ & $82.7 \pm 1.4$ & $72.9 \pm 1.5$ & $84.6 \pm 10.5$ \\
August & $25.0 \pm 1.0$ & $15.5 \pm 1.1$ & $77.7 \pm 3.1$ & $82.9 \pm 1.3$ & $74.5 \pm 1.4$ & $92.9 \pm 17.6$ \\
September & $23.0 \pm 1.0$ & $14.5 \pm 1.09$ & $75.1 \pm 3.3$ & $82.8 \pm 1.5$ & $71.2 \pm 1.5$ & $157.8 \pm 36.5$ \\
October & $20.3 \pm 1.0$ & $15.3 \pm 1.13$ & $81.2 \pm 3.5$ & $82.6 \pm 1.7$ & $67.4 \pm 1.6$ & $220.0 \pm 57.0$ \\
November & $17.5 \pm 1.1$ & $12.0 \pm 1.17$ & $80.5 \pm 3.6$ & $86.5 \pm 1.8$ & $62.8 \pm 1.8$ & $238.4 \pm 59.6$ \\
December & $18.5 \pm 1.1$ & $10.8 \pm 1.19$ & $79.9 \pm 3.6$ & $85.1 \pm 2.0$ & $64.4 \pm 1.9$ & $268.2 \pm 65.1$ \\
\hline
\end{tabular}

Tmax, temperature maximum; Tmed, temperature medium; Tmin, temperature minimum; RHmin, relative humidity minimum; Hmax, relative humidity maximum; THI, temperature humidity index. 


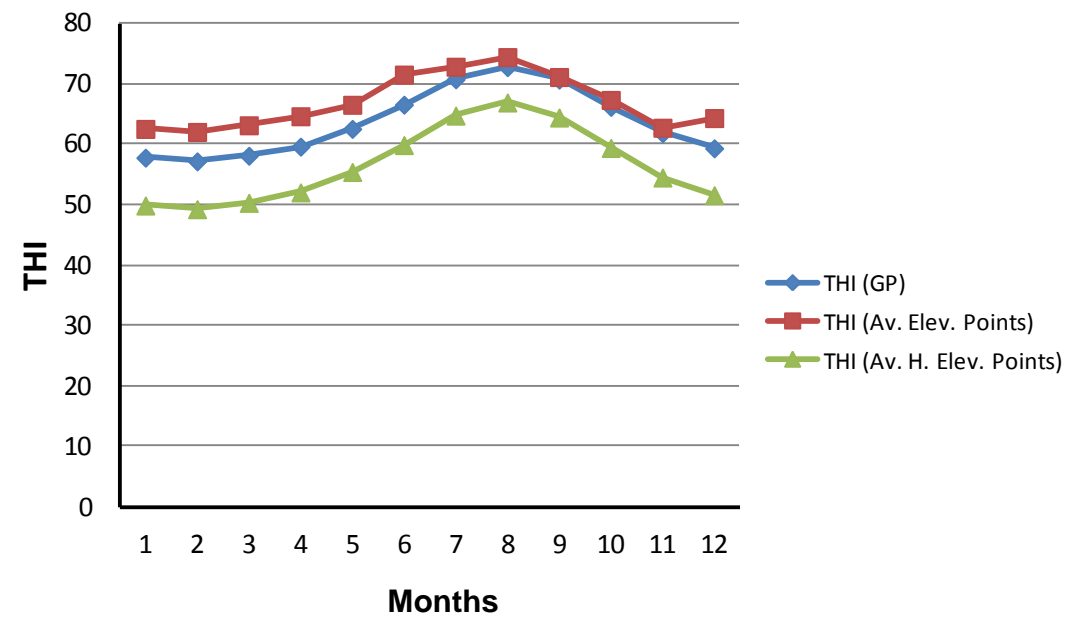

Figure 1. Mean of temperature humidity index (THI) calculated through the sensors placed in different points located in the island, (Av. Elev. Points), grazing points (GP) and higher than $500 \mathrm{~m}$ (Av. H. Elev. Points). Results obtained in cold months (December, January, February, and March) are statistically lower ( $\mathrm{p}<0.001)$ as compared with warm months (June, July, August, and September).

observed in oocytes meiotic maturation rate as well as in the embryonic developmental ability. On average, oocytes meiotic maturation was $78.4 \pm 8.0 \%$ vs $44.3 \pm 8.1 \%$ ( $p<0.001)$ respectively for colder and warmer months. This significant decline was the result of a high percentage of meiotic arrest in the stage of telophase I. In fact, in the warm period $36.2 \%( \pm 2.7)$ were considered blocked at the stage of telophase I while in the colder months, only $8.0 \%( \pm 0.7)$ were considered blocked at this stage (Table 2). Similarly cleavage and further embryonic development after IVF were higher $(\mathrm{p}<0.05)$ during the cold period $(78.0 \pm 4.5$; $53.8 \pm 5.8$, for cleavage and embryonic development) as compared with the hot period $(48.2 \pm 4.2 ; 36.3 \pm 3.3$ respectively cleavage and embryonic development) (Table 3). Considering oocyte's maturation by cumulus expansion, no statistical differences were obtained between cold and warm periods $(94.6 \% \pm 1.2$ vs $80.3 \% \pm 4.1$, respectively).

\section{Effect of heat shock on cumulus and nuclear maturation and embryo development}

Out of 891 cultured oocytes, a total of 789 were considered matured as evaluated by cumulus expansion. Besides maturated oocytes in the HS2 group (84.6 $44.3 \%)$ were lower than in the HS1 $(90.4 \pm 1.0 \%)$ no statistical differences were observed among results, as well as when compared to the control $(90.9 \pm 1.5 \%)$. Nevertheless, when maturation was evaluated by meiosis development, for each heat shock treatment (HS1, HS2), greatest number of oocytes was not progressing to MetaphaseII (MII), and most of them got arrested in the stages between germinal vesicle breakdown (GVBD) and Telophase I (Table 4). As only oocytes reached MII are considered nuclearly matured,

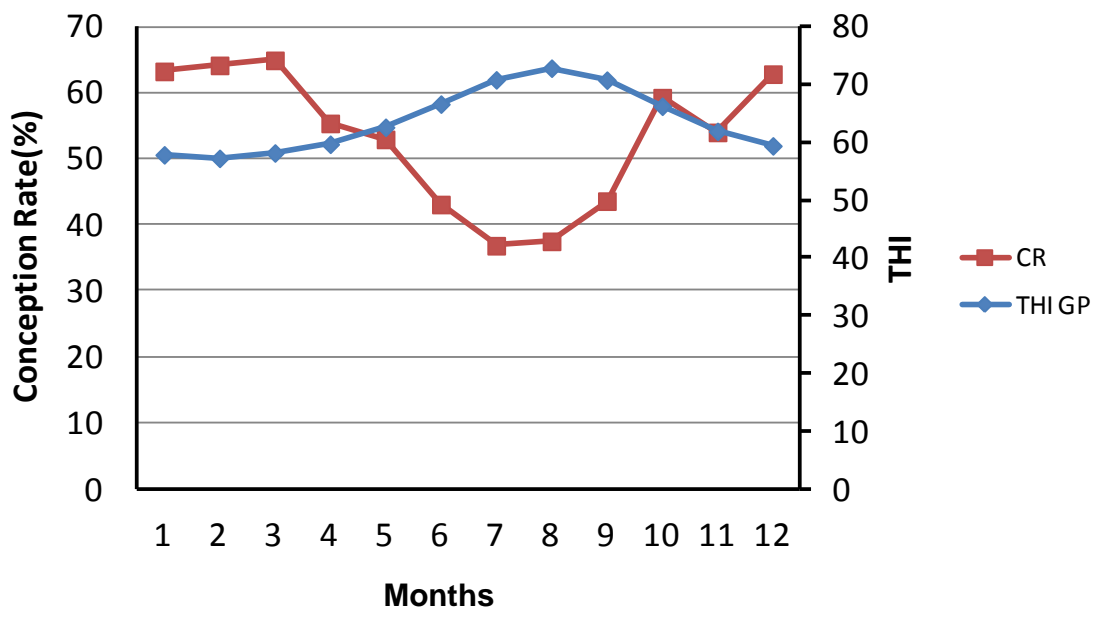

Figure 2. Relation between temperature humidity index (THI) calculated though the sensors placed in grazing points and conception rate (CR) as measured by the non-return in estrus at least 90 days after the first insemination after calving. Results obtained for CR in cold months are statistically higher $(\mathrm{p}<0.001)$ as compared with warm months. 
Table 2. Nuclear maturation of bovine oocytes during IVM in warm and cold months

\begin{tabular}{lcccccc}
\hline \multirow{2}{*}{ Seasons } & \multirow{2}{*}{ Oocytes fixated } & \multicolumn{5}{c}{ Meiosis developmental stages (\%) } \\
\cline { 3 - 7 } & & GVBD & MI & AI & TI & MII \\
\hline Cold months $^{1}$ & 125 & $3.2 \pm 0.4$ & $8.8 \pm 0.8$ & $1.6 \pm 0.2$ & $8.0 \pm 0.7$ & $78.4 \pm 8.0^{\mathrm{a}}$ \\
Warm months $^{2}$ & 124 & $8.8 \pm 0.4$ & $8.8 \pm 0.6$ & $1.6 \pm 0.2$ & $36.2 \pm 2.7$ & $44.3 \pm 8.1^{\mathrm{b}}$ \\
\hline
\end{tabular}

IVM, in vitro maturation; GVBD, germinal vesicle breakdown; MI, Metaphase 1; AI, Anaphase 1; TI, TelophaseI; MII, MetaphaseII; SEM, standard error of the mean.

${ }^{1}$ Cold moths include December, January, February, March.

${ }^{2}$ Warm months include June, July, August, and September Oocytes only were considered maturated at MII.

Data represents mean \pm SEM.

${ }^{\mathrm{a}, \mathrm{b}}$ Represents statistical differences $(\mathrm{p}<0.05)$.

Table 3. Embryonic developmental rate in warm and cold months

\begin{tabular}{lcccccc}
\hline Seasons & $\begin{array}{c}\text { Number of } \\
\text { oocytes }\end{array}$ & $\begin{array}{c}\text { Cumulus } \\
\text { expansion (\%) }\end{array}$ & $\begin{array}{c}\text { Cleavage (\%) } \\
\text { (Day 2) }\end{array}$ & $\begin{array}{c}\text { Morula (\%) } \\
\text { (Day 9) }\end{array}$ & $\begin{array}{c}\text { Blastocyst (\%) } \\
\text { (Day 9) }\end{array}$ & $\begin{array}{c}\text { Embryo } \\
\text { development (\%) }\end{array}$ \\
\hline Cold months $^{1}$ & 223 & $94.6 \pm 1.2$ & $78.0 \pm 4.5$ & $27.8 \pm 3.7$ & $26.0 \pm 7.2$ & $53.8 \pm 5.8^{\mathrm{a}}$ \\
Warm months $^{2}$ & 234 & $80.3 \pm 4.1$ & $48.2 \pm 4.2$ & $19.6 \pm 2.4$ & $16.6 \pm 2.4$ & $36.3 \pm 3.3^{\mathrm{b}}$ \\
\hline
\end{tabular}

${ }^{1}$ Cold month includes December, January, February, and March.

${ }^{2}$ Warm months includes June, July, August, and September.

${ }^{a, b}$ Indicates statistical mean differences $(\mathrm{p}<0.05)$. All the percentages are based on the number of survived oocytes.

Day 0 represents the insemination day.

from the 404 fixated oocytes, a statistical decrease in nuclear maturation rate $(\mathrm{p}<0.05)$ was observed between control, HS1 and HS2, $(78.4 \pm 8.0 \%, 21.7 \pm 3.1 \%$ and $8.9 \pm 2.2$, respectively) (Table 4). After IVF, this predisposition was also observed in cleavage rate $(\mathrm{p}<0.05)$ ranging from $70.7 \pm 2 \%$ in the control to $35.4 \pm 1 \%$ and $15.5 \pm 2 \%$, respectively for HS1 and HS2. The same pattern was observed for embryonic development, in which morula and blastocysts decreased from $48.0 \pm 1 \%$ in the control to $20.5 \pm 1 \%$ and $9.5 \pm 2 \%$, respectively for $\mathrm{HS} 1$ and HS2 (Figure 3).

\section{DISCUSSION}

The present study aimed to evaluate in vivo and in vitro effect of weather conditions in a dry-summer subtropical climate, in relation to the conception rate of grazing all year Holstein cows. Then, as a complement of this study, to mimic warm temperatures, heat shock was performed on oocytes during maturation period, evaluating their nuclear maturation and further development to the stage of blastocysts after IVF. Results of IVF were also evaluated considering hot and cold seasons. These experiments are significant because they show that not only elevated temperatures affecting reproductive performances of Holstein cows, but also affect meiosis competence of oocytes and even further development after IVF. Heat stress is, in fact, the major contributing factor to the low fertility of dairy cows inseminated in hot seasons as previously observed by some authors (e.g. Ray et al., 1992; White et al., 2002; Collier et al., 2006; Ferreira et al., 2011). However fertility in the Azores is relatively high, when compared with other temperate zones (Sieuve de Menezes et al., 2011), the CR was about half during warmer months (June, July, August and September), when compared with the cold period (December, January, February and March).

Regarding Terceira island conditions the overall yearly CR was lower than results published by Sieuve de Menezes et al. (2011) (55\% vs 73\%, respectively). The reason for this can be explained by differences in study design. Our study only considered Holstein cows that became pregnant at the first insemination after calving, while Sieuve de Menezes et al. (2011) considered different breeds and also nulliparous and multiparous lactating cows, as well as multiple

Table 4. Nuclear maturation of bovine oocytes heat shocked at different temperatures during IVM

\begin{tabular}{lcrrrrr}
\hline \multirow{2}{*}{ Treatment } & \multirow{2}{*}{ Oocytes fixated } & \multicolumn{5}{c}{ Meiosis developmental stages (\%) } \\
\cline { 3 - 7 } & & GVBD & MI & AI & TI & MII \\
\hline C & 125 & $3.2 \pm 0.4$ & $8.8 \pm 0.8$ & $1.60 \pm 0.21$ & $8.00 \pm 0.7$ & $78.4 \pm 8.0^{\mathbf{a}}$ \\
HS1 & 157 & $36.3 \pm 5.3$ & $17.2 \pm 2.3$ & $6.4 \pm 0.8$ & $18.5 \pm 1.3$ & $21.7 \pm 3.1^{\mathbf{b}}$ \\
HS2 & 122 & $38.7 \pm 7.3$ & $34.67 \pm 6.4$ & $5.6 \pm 1.4$ & $12.1 \pm 3.7$ & $8.9 \pm 2.2^{\mathbf{c}}$ \\
\hline
\end{tabular}

IVM, in vitro maturation; GVBD, germinal vesicle breakdown; MI, Metaphase I; AI, Anaphase I; TI, Telophase I; MII, Metaphase II; C, control (38.5 $\left.{ }^{\circ} \mathrm{C}\right)$, HS1, heat shock $1\left(39.5^{\circ} \mathrm{C}\right)$; HS2, $40.5^{\circ} \mathrm{C}$; SEM, standard error of the mean.

Data represents mean \pm SEM.

${ }^{a, b, c}$ Represents statistical mean differences $(\mathrm{p}<0.05)$. 


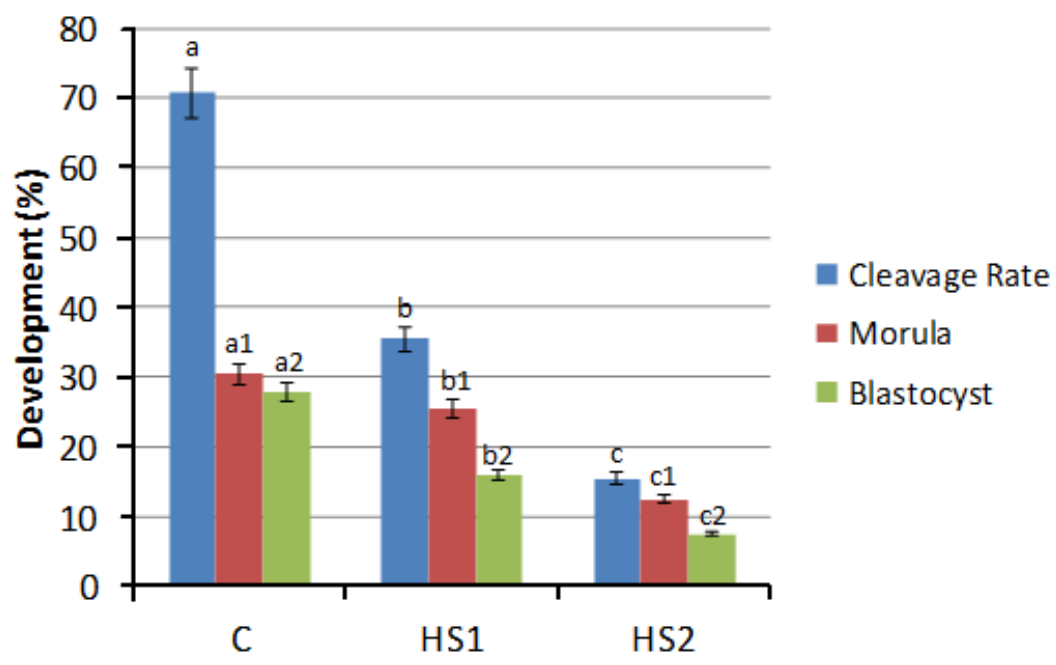

Figure 3. Embryo cleavage and development after in vitro fertilization (IVF). Every point represents the mean of 40 oocytes fertilized on each iteration. $\mathrm{C}=$ control group, HS1 and HS2 represents heat shock 1 and heat shock 2 . Insemination and embryo development was performed at $38.5^{\circ} \mathrm{C}$. Cleavage was determined $48 \mathrm{~h}$ after insemination. Embryo development was evaluated on day 6 (morula) and day 9 (blastocysts). Results marked with a,b,c; a1,b1,c1; a2,b2,c2, differ statistically (p<0.05).

breeding for each animal. For the same reason, results were also different in the warmer period in which in the present study CR was $37 \%$ to $38 \%$, whereas from Sieuve de Menezes it was $42 \%$. Research developed by Yaser et al. (1999) had shown that 90 days non return rate, as considered in the present study, declined during warm months in all locations of Florida and Georgia. That study indicated that the magnitude of the hot months was directly related to non-return rate after insemination, based on the location and consequently THI levels. Also in our study, it was clear that THI is inversely proportional to CR. In warm periods when THI levels were high, CR was very low and vice versa in cold periods. Moreover, research developed by Yaser et al. (1999) indicates that impaired infertility in warm months increased as cows were located further in South Georgia and Florida. It could be expected that location would affect scale of summer, but it was prominent that such effects were observed over relatively short distances, as observed in our study between high and low altitudes. Since THI levels play a crucial role in CR, it can be suggested that cooling systems during summer may have a beneficial effect on cow's fertility by maintaining THI similar to winter, besides it has been proven that cooling cows for limited number of days will not be completely successful (Ealy et al., 1993). In our conditions we can suggest, it would improve cow CR in hot periods, if breeding animals were moved to higher altitude points where THI levels are lower.

Several physiological factors that can disrupt establishment of pregnancy can be changed by high THI. These can occur before ovulation, on the day of insemination and during embryo and fetal development. Heat stress can affect endometrial prostaglandin secretion
(Putney et al., 1989) and conceivably, lead to luteolysis and embryonic loss. On the other hand, when appetite and dry matter intake are considerably reduced by heat stress, cows remain longer in negative energy balance, increasing the length of postpartum anestrus and the calving conception interval (De Rensis and Scaramuzzi, 2003). This can be the result of a physiological mechanism, in which GnRH surge is blocked in the hypothalamus, affecting hypophysis gland activity and consequently follicular development. Moreover, heat stress during early pregnancy in cattle reduces conceptus weight which may lead to embryonic mortality (Biggers et al., 1987). Studies developed by Torres-Junior et al. (2008) indicated that blood progesterone concentrations fluctuate depending on environmental temperatures. Therefore, if heat stress alters the metabolism of progesterone, it would ultimately affect follicles and especially corpus luteum development. Increase in body temperatures and tendency to modify progesterone concentration also alter endometrial secretion of mucus, forming an unfavorable environment for conceptus growth. In the present study an immediate enhancement of $\mathrm{CR}$ is observed in the month of October compared to warmer periods, as observed in other studies (Roth et al., 2000; Roth and Hansen, 2004). This delayed effect can be explained as in October, THI and Tmax levels were dropped from 73.9 to 65.6 and $23.8^{\circ} \mathrm{C}$ to $18.9^{\circ} \mathrm{C}$, respectively.

The in vitro analysis has shown that during warm months not only cow conception rate is declined but also embryo developmental rate was significantly reduced. Oocytes retrieved during warmer periods have less ability to develop into embryos as compared to oocytes retrieved during cold periods. During warmer periods nuclear maturation of oocytes is arrested in early stages of meiotic 
maturation (Maya Soriano et al., 2013). Our study is in agreement with research conducted by El-Sayed et al. (2006) and Ferreira et al. (2011) in which oocytes retrieved during the warmer months had lower capability to undergo embryo developmental stages. Damage of oocytes quality during warmer periods, leading to meiotic arrest of oocytes at anaphase and telophase stages, could be provoked by several factors. One possibility is that metabolic changes in preantal follicles, follicular fluid and dominant follicles affect the quality of both oocytes and granulosa cells which were postulated in dairy cows with negative energy balance during early postpartum period (Britt, 1994; Leroy et al., 2004). Our results clearly demonstrated that cow's exposure to thermal stress during warm periods affect maternal physiological responses on follicular and consequently oocyte quality, leading a low embryonic development.

Further heat shock on oocytes was performed to understand the relationship of meiotic maturation embryonic development rate. This part of the study gives a new insight that for every degree rise in temperature, in every stage of heat shock treatment, nearly $50 \%$ decline in nuclear maturation rate occurred, as well as in the cleavage rate and embryos development. Research conducted by Ju et al. (1999); Wang et al. (2001) and Tseng et al. (2004) showed prolonged heat shock on bovine oocytes maturation leads to the alteration in nuclear structures, micro tubules, and micro filaments. These abnormalities in the chromosomes increase with time of heat shock treatment, inhibiting polymerization of meiotic spindles. Microtubules disruption also affects cytoplasmatic organelles transport such as oocyte mitochondrial distribution (Sun et al., 2001). Even exposure of oocytes to room temperature as well as to low temperatures for short duration causes depolymerization of the spindles (Aman and Parks, 1994). Baugarter and Chrisman (1987) working with mice, reported maternal heat stress may also cause disruption of meiosis 1 spindle in oocyte's maturation which in turn may influence meiosis development stage and polar body extrusion. In contrast to our results Payton et al. (2004) and Edwards et al. (2005) showed bovine oocytes cultured at $41{ }^{\circ} \mathrm{C}$ did not have a compromise ability to undergo nuclear progression to MII or cytoplasmic maturation (cortical granule translocation to the oolemma). However, our results agree with Tseng et al. (2004) and Paula-Lopes et al. (2008) where it was clearly demonstrated that heat-shocked bovine oocytes meiosis development stage were arrested in the initial stages GVBD and Metaphase 1. Moreover, bovine oocytes blocked at beginning stages of meiosis would have more impact on apoptosis activation (Tseng et al., 2004; Roth and Hansen, 2005) as meiotic spindle was found disrupted in IVM during heat shock, resulting in chromosomal dispersion, polyploidy and ultimately death of the oocytes.

\section{CONCLUSION}

Although several studies have clearly shown a detrimental effect of summer heat stress on bovine reproduction, to our knowledge this has been the first time this phenomenon is related with meiotic maturation and embryonic ability to develop in vitro after stress conditions. In vivo studies have demonstrated that, up to a THI of 59, a decrease in CR occurs when AI is performed 60 to 90 days after calving. This falling in fertility was confirmed by the in vitro experiments, in which oocytes nuclear maturation and further in vitro development decreases significantly in warmer periods. Heat-shocked oocyte's maturation also confirmed this low ability of oocytes to maturate and develop after IVF.

As THI values in hot months are lower in highest elevations, one could propose to locate animals in high elevation points during the warmest season to reduce the impact of heat stress in cow conception rate. Additional studies are needed to evaluated short time heat stress effect on both in vivo and in vitro of bovine. Moreover, developmental and growth factor genes on heat stressed oocytes and embryos can provide additional information, in the cellular level, about the factors responsible for the impairment of fertility status in hottest periods.

\section{ACKNOWLEDGMENTS}

Project supported by the Azorean Agency for Science and Technology, Grant BD M3.1.2/F/044/2011. CITA-A is also fully acknowledged.

\section{REFERENCES}

Aman, R. R and J. E. Parks. 1994. Effects of cooling and rewarming on the meiotic spindle and chromosomes of in vitro-matured bovine oocytes. Biol. Reprod. 50:103-110.

Alexander, V. S. 2010. Effect of two types of stress (heat shock/high temperature and malnutrition/serum deprivation) on porcine ovarian cell functions and their response to hormones. J. Exp. Biol. 213:2125-2130.

Azevedo, E. B. 1996. Modelling of Insular Climate at Local Scale. Model CIELO Applied to Terceira. Ph.D. Thesis, Universidade dos Açores, Angra do Heroísmo, Portugal.

Badinga, L., R. J. Collier, W. W. Thatcher, and C. J. Wilcox. 1985. Effects of climatic and management factors on conception rate of dairy cattle in subtropical environment. J. Dairy Sci. 68:7885 .

Badinga, L., W. W. Thatcher, T. Diaz, M. Drost, and D. Wolfenson. 1993. Effect of environmental heat stress on follicular development and steroidogenesis in lactating Holstein cows. Theriogenology 39:797-810.

Baumgartner, A. P and C. L. Chrisman. 1987. Embryonic mortality caused by maternal heat stress during mouse oocyte maturation. Anim. Reprod. Sci. 14:309-316. 
Britt, J. H. 1994. Follicular development and fertility: Potential impacts of negative energy balance. In: Proc. Nat. Reprod. Symp. 103-112.

Biggers, B. G., R. D. Geisert, R. P. Wetteman, and D. S. Buchanan. 1987. Effect of heat stress on early embryonic development in the beef cow. J. Anim. Sci. 64:1512-1518.

Collier, R. J., G. E. Dahl, and M. J. Van-Baale. 2006. Major advances associated with environmental effects on dairy cattle. J. Dairy Sci. 89:1244-1253.

De Rensis, F. and R. J. Scaramuzzi. 2003. Heat stress and seasonal effects on reproduction in the dairy cow-A review. Theriogenology 60:1139-1151.

Ducibella, T. and J. Buetow. 1994. Competence to undergo normal, fertilization-induced cortical activation develops after metaphase I of meiosis in mouse oocytes. Dev. Biol. 165:95104.

Edwards, J. L. and P. J. Hansen. 1997. Differential responses of bovine oocytes and preimplantation embryos to heat shock. Mol. Reprod. Dev. 46:138-145.

Edwards, J. L., A. M. Saxton, J. L. Lawrence, R. R. Payton, and J. R. Dunlap. 2005. Exposure to a physiologically relevant elevated temperature hastens in vitro maturation in bovine oocytes. J. Dairy Sci. 88:4326-4333.

Ealy, A. D., M. Drost, and P. J. Hansen. 1993. Developmental changes in embryonic resistance to adverse effects of maternal heat stress in cows. J. Dairy Sci. 76:2899-2905.

El-Sayed, A. M., F. Hoelker, D. Rings, D. Slilew, E. Jennen, M. A. Tholen, K. Sirard, and D. Schellander Tesfaye. 2006. Largescale transcriptional analysis of bovine embryos biopsies in relation to pregnancy success after transfer to recipients. Physiol. Genomics 28:84-96.

Faheem, M. S., I. Carvalhais, A. Chaveiro, and F. Moreira da Silva. 2011. In vitro oocyte fertilization and subsequent embryonic development after cryopreservation of bovine tissue, using an effective approach for oocyte collection. Anim. Reprod. Sci. 125:49-55.

Ferreira, R. M., H. Ayres, M. R. Chiaratti, M. L. Ferraz, A. B. Araújo, C. A. Rodrigues, Y. F. Watanabe, A. A. Vireque, D. C. Joaquim, L. C. Smith, F. V. Meirelles, and P. S. Baruselli. 2011. The low fertility of repeat-breeder cows during summer heat stress is related to a low oocyte competence to develop into blastocysts. J. Dairy Sci. 94:2383-2392.

Garcia Ispierto, I., F. Lopez-Gatius, G. Bech-Sabat, P. Santolaria, J. L. Yaniz, C. Nogareda, F. De Rensis, and M. Lopez-Bejar. 2007. Climate factors affecting conception rate of high producing dairy cows in northeastern spain. Theriogenology 67:1379-1385.

Hansen P. J., M. Drost, R. M. Rivera, F. F. Paula-Lopes, Y. M. AlKatanani, C. E. Krininger, and C. C. Chase. 2001. Adverse impact of heat stress on embryo production: causes and strategies for mitigation. Theriogenology 55:91-103.

Hosoe, M. and Y. Shioya.1997. Distribution of cortical granules in bovine oocytes classified by cumulus complex. Zygote 5:371376.

Ju, J. C. 1999. The Effect of Heat Shock on the Developmental Competence and Activation of Bovine Oocytes. Ph.D Thesis. Cornell University, Ithaca, NY, USA.

Leroy, J. L. M. R., T. Vanholder, J. R. Delanghe, G. Opsomer, A. Van Soom, P. E. J. Bols, J. Dewulf, and A. de Kruif. 2004.
Metabolic changes in follicular fluid of the dominant follicle in high-yielding dairy cows early postpartum. Theriogenology 62:1131-1143.

Lawrence, J. L., R. R. Payton, J. D. Godkin, A. M. Saxton, F. N. Schrick, and J. L. Edwards. 2004. Retinol improves development of bovine oocytes compromised by heat stress during maturation. J. Dairy Sci. 87:2449-2454.

Maya-Soriano, M. J., F. López-Gatius, C. Andreu-Vázquez, and M. López-Béjar. 2013. Bovine oocytes show a higher tolerance to heat shock in the warm compared with the cold season of the year. Theriogenology 79:299-305.

Paula-Lopes, F. F., M. Milazzotto, M. E. O. A. Assumpcao, and J. A. Visintin. 2008. Heat shock-induced damage in bovine oocytes. Reprod. Fertil. Dev. 43:208.

Payton, R. R., R. Romar, P. Coy, A. M. Saxton, J. L. Lawrence, and J. L. Edwards. 2004. Susceptibility of bovine germinal vesicle-stage oocytes from antral follicles to direct effects of heat stress in vitro. Biol. Reprod. 71:1303-1308.

Pires, M. F. A., A. M. Ferreira, H. M. Saturnino, and R. L. Teodoro. 2002. Pregnancy rate in holstein females confined in free stall, in summer and winter. Arq. Bras. Med. Vet. Zootec. 54:57-63.

Putney, D. J., S. Mullins, W. W. Thatcher, M. Drost, and T. S. Gross. 1989. Embryonic development in superovulated dairy cattle exposed to elevated ambient temperatures between the onset of estrus and insemination. Anim. Reprod. Sci 19:37-51.

Ray, D. E., T. J. Halbach, and D. V. Armstrong. 1992. Season and lactation number effects on milk production and reproduction in dairy cattle in Arizona. J. Dairy Sci. 75:2976-2983.

Roth, Z., A. Arav, A. Boar, Y. Zeron, and D. Wolfenson. 2001. Improvement of quality of oocyte collected in the autumn by enhanced removal of impaired follicles from previously heatstressed cows. Reproduction 122:737-744.

Roth, Z., R. Meidan, R. Braw-Tal, and D. Wolfenson. 2000. Immediate and delayed effects of heat stress on follicular development and its association with plasma FSH and inhibin concentration in cows. J. Reprod. Fertil. 120:83-90.

Roth, Z. and P. J. Hansen. 2004. Involvement of apoptosis in disruption of developmental competence of bovine oocytes by heat shock during maturation. Biol. Reprod. 71:1898-1906.

Roth, Z. and P. J. Hansen. 2005. Disruption of nuclear maturation and rearrangement of cytoskeletal elements in bovine oocytes exposed to heat shock during maturation. Reproduction 129: 235-244.

Sieuve de Menezes, S., A. Chaveiro, and F. Moreira da Silva. 2011. Effect of climatic conditions on reproductive performance of grazing heifers and lactating cows in the Azores, a warm temperate region. Theriogenol. Insight 1:89-97.

Sun, Q. Y., G. M. Wu, L. Lai, K. W. Park, R. Cabot, H. T. Cheong, B. N. Day, R. S. Prather, and H. Schatten. 2001. Translocation of active mitochondria during pig oocyte maturation, fertilization and early embryo development in vitro. Reproduction 122:155-163.

Torres-Júnior, J. R., M. F. Pires, W. F. Sá, M. A. Ferreira, J. H. M. Viana, L. S. A. Camargo, A. A. Ramos, I. M. Folhadella, J. Polisseni, C. Freitas, C. A. A. Clemente, M. F. Sá Filho, F. F. Paula-Lopes, and P. S. Baruselli. 2008. Effect of maternal heatstress on follicular growth and oocyte competence in Bos indicus cattle. Theriogenology 69:155-166.

Tseng, J. K., C. H. Chen, P. C. Chou, S. P. Yeh, and J. C. Ju. 2004. 
Influences of follicular size on parthenogenetic activation and in vitro heat shock on the cytoskeleton in cattle oocytes. Reprod. Domest. Anim. 39:146-153.

Wang, W., M. Hosoe, R. Li, and Y. Shioya. 1997. Development of the competence of bovine oocytes to release cortical granules and block polyspermy after meiotic maturation. Dev. Growth Differ. 39:607-615.

Wang, W. H., L. Meng, R. J. Hackett, R. Odenbourg, and D. L. Keefe. 2001. Limited recovery of meiotic spindles in living human oocytes after cooling-rewarming observed using polarized light microscopy. Hum. Reprod. 16:2374-2378.
White, F. J., R. P. Wettemann, M. L. Looper, T. M. Prado, and G. L. Morgan. 2002. Seasonal effects on estrous behaviour and time of ovulation in non-lactating beef cows. J. Anim. Sci. 80: 3053-3059.

Yaser, M. A., D. W. Webb, and P. J. Hansen. 1999. Factors affecting seasonal variation in 90-Day nonreturn rate to first service in lactating holstein cows in a hot climate. J. Dairy Sci. 82:2611-2616.

Yousef, M. K. 1985. Stress physiology: definition and terminology. Stress Physiology in livestock. In: Basic principles (Ed. M. K. Yousef) Vol. 1, pp. 3-7. CRC Press, Boca Raton, FL, USA. 